\title{
Beware the long flight home
}

$\mathrm{O}$ ctober 8, 2005. An immense earthquake jars northern Pakistan and India. There are initial images of schools and houses crumbling, and people being buried, rescued, injured and killed - tens of thousands dead with tolls rising rapidly. A desperate race to meet medical needs as the wounds and fractures multiply.

Within one week the Canadian Relief Foundation sends out a call for volunteers to join a team going to Pakistan, leaving in just two days. I reread the notice thinking "I wish I could go." Then I remember a woman I had met recently who would ask people "If you could do anything in the world you wanted to, what would you do?" And when she received a response she would say "Well, why don't you?"

I quickly decide that any excuse I can make is laughable...I contact my residency program director, organize the required paperwork, and ready my backpack for Pakistan.

I arrive at the airport and meet the eleven other physicians, nurses and paramedics from across Canada with whom I will be working. I am part of the team based in Bagh, a devastated town near the earthquake epicentre, while the surgeons on the team remain in Islamabad, working at the hospital.

After landing in Islamabad we drive along the narrow, curvy, dangerous road to Bagh. The views of the mountains and valleys are breathtaking and affirm the legends I have heard about the beauty of Kashmir. In stark contrast to this brilliance are the homes along the landscape - intact structures from a distance become slabs of metal perched over rubble when closer. Displaced families live in adjacent tents.

Based in Bagh, we go out to villages each day. At the first village, before even beginning to unpack, I am handed a listless child. I feel a moment of panic. Start with the basics, I tell myself. I conduct my assessment and decide on a course of treatment. The day

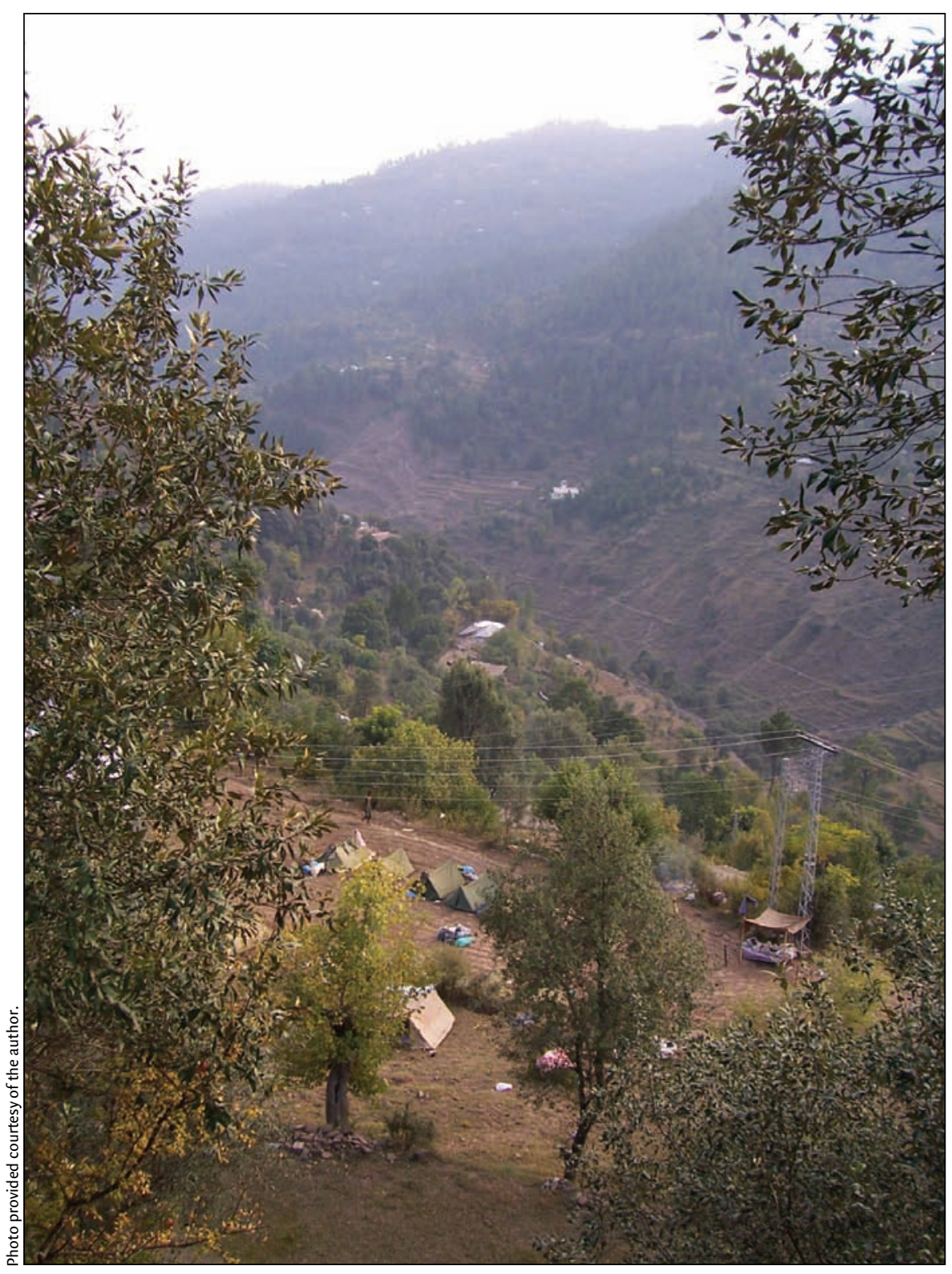

In stark contrast to the breathtaking beauty of the landscape, homes are in rubble and families live in tents.

has started. I have faced my first patient and from that moment on, there is no rest, no time to think.

We collectively see thousands of patients over the following weeks. The cases range from routine primary care to viciously infected wounds, poorly healed fractures, and other earthquakerelated injuries. I run a women's clinic. As I lead women and girls into my ex- amination tent I am repeatedly struck by the beauty of their smiles once they move their hijabs. We are all amazed by the children - the ones who laugh and run away from our waiting tetanus vaccine needles, who stalwartly (or loudly) withstand our debridements, or who are brought by an aunt or a grandfather because their parents have perished. The elderly are carried to us 
still on their beds from even more remote locations.

We are blessed with perfect weather. We sleep outside and I stare in wonder at the thousands of lights in the mountains and in the sky.

It comes time to leave and we know there are still scores of untreated patients left in remote villages as the cold and snow of winter loom.

We join with our colleagues in Islamabad. There the operating rooms have been running 24 hours a day for weeks, and the rush is only beginning to ebb. Petrified children are crying pre- and post-operatively. The operating rooms have two concurrent surgeries occurring in each. Cases of measles are mounting and I see several tetanus patients on ventilators.

Here I see a 6-year-old girl with an infected brain herniation being debrided by a neurosurgeon. A 3-year-old boy whose entire left leg has been "degloved" when being aggressively pulled from the rubble - his underlying muscle is pathetically exposed while the surgeon assesses the possibility of a skin graft. A 9-year-old boy with quiet, dark eyes, and a left below-the-knee amputation. Children with elaborate external fixations and gaping open wounds to be cleaned.

The charts read "2-year-old girl. EQU victim. No family. Tibia fracture" and other similar, blunt descriptions. I perform whatever task is needed - assisting the surgeons, running for supplies, holding a child's hand. The suffering of these children is beyond my comprehension.

We wheel the last patient of the day, a Io-year-old girl, out of the operating room to be returned to her family. The surgeon calls her name, and a tiny girl, not more than 7 years old, emerges from around the corner.

Her only surviving family member.

It is time to return to Canada, to return home. It is a long plane ride home, and now the little girl's story, along with every other story I have heard over the past month, tumble over each other in my mind. We were so busy over the past weeks that there was little time to contemplate. Now, during the 16 -hour plane ride, I find the sadness overwhelming. I can't stop thinking, and I don't know how I will face my home.

Monika Dutt

Toronto, Ont.

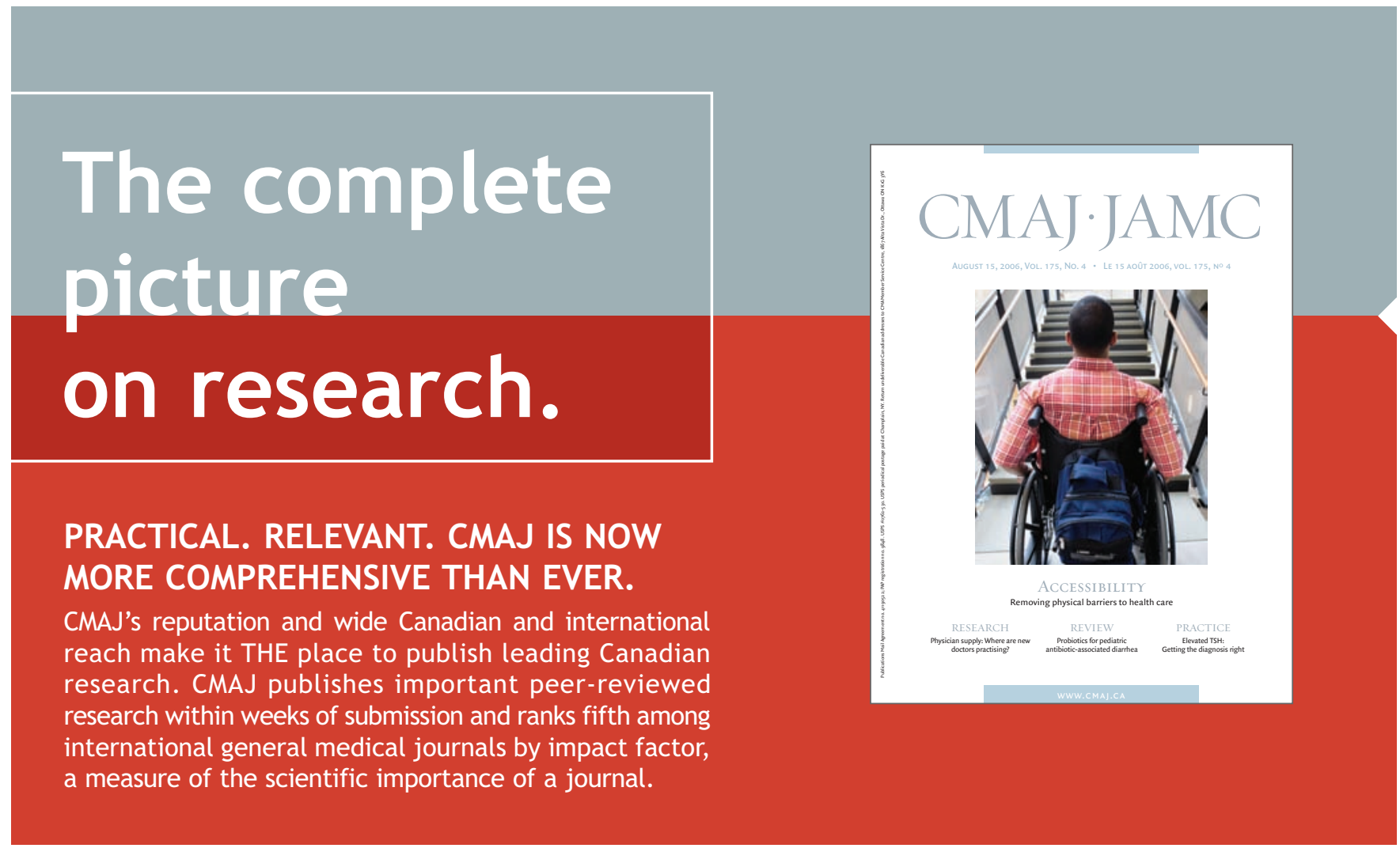

The essential read. ${ }^{\mathrm{TM}}$ 